\title{
The role of primary cemented total hip arthroplasty in the management of fractures of the neck of femur in the elderly population
}

\author{
Yeshwanth Subash*, Jagadeesh B., Ravikrishna R., Prabhu Manickam
}

Department of Orthopaedics, Saveetha Medical College and Hospital, Thandalam, Chennai, Tamil Nadu, India

Received: 08 October 2017

Revised: 26 October 2017

Accepted: 27 October 2017

*Correspondence:

Dr. Yeshwanth Subash,

E-mail: djyesh76@gmail.com

Copyright: () the author(s), publisher and licensee Medip Academy. This is an open-access article distributed under the terms of the Creative Commons Attribution Non-Commercial License, which permits unrestricted non-commercial use, distribution, and reproduction in any medium, provided the original work is properly cited.

\begin{abstract}
Background: Femoral neck fractures are common injuries in the elderly population and are associated with high rates of morbidity and mortality. The aim of surgical intervention in these elderly patients is to restore them to the prefracture status as rapidly as possible. The aim of this study was to evaluate the role of total hip arthroplasty as a primary option in the management of these fractures and to compare the results with studies of other authors as available in literature.

Methods: 45 patients with femoral neck fractures treated with cemented total hip arthroplasty were studied from January 2011 to January 2013 and were followed up for a minimum period of two years.

Results: There were 18 males and 27 females ranging from 60 to 75 years of age. Mean age was 64.6 years. Majority $(80 \%)$ of the fractures were completely displaced, Garden type 4 fractures followed by type 3 in $20 \%$ of cases. The most common mode of injury was a simple slip and fall. Excellent results were seen in 17 patients, good results in 24 patients and fair results in 4 patients. No poor results were seen.

Conclusions: Cemented total hip arthroplasty is a very useful procedure for the primary treatment of femoral neck fractures in elderly patients. This procedure markedly improves the functional status of the patients and gives good functional results.
\end{abstract}

Keywords: Neck of femur, Gardens type, Total hip, Harris score

\section{INTRODUCTION}

The rising number of femoral neck fractures is well documented worldwide. The incidence of these fractures rises exponentially with age. This increase becomes significant from the age of 60 years in women and later in men. The rising number of fractures is due to the increasing longevity of the population. ${ }^{1}$ The majority of these fractures are due to a combination of age related factors, principally age related bone loss and trauma which is usually a simple fall and other causes are also seen as in fall from a height and road traffic accidents. They are often associated with high rates of morbidity and mortality
Various treatment methods are available for the management of these fractures depending upon factors such as age of the patient, quality of the bone, type of fracture as per the classification, timing of surgery as well as the associated co morbid conditions which must be taken into account. Conservative management has largely been given up due to the fact that a prolonged period of immobilization and recumbency is associated with a high rate of morbidity and complications such as non-union, and is only reserved in cases where the patient has associated severe co morbid conditions where surgical management would not be possible. Internal fixation is the treatment of choice in young individuals where every effort should be made to preserve the femoral head. 
Internal fixation is associated with complications such as non-union as well as the risk of avascular necrosis especially if there is a delay in surgery and if proper indications have not been met as per established protocols. In elderly patients, especially over the age of 60 years, preservation of the femoral head would not be a viable option and the procedures of choice in the management of these fractures would either be a hemiarthroplasty or a total hip replacement. ${ }^{2,3}$

Hemiarthroplasty avoids the complications which have been associated with internal fixation, but it has its own complications especially in the case of younger individuals where high rates of acetabular erosion and protrusion acetabuli have been seen requiring a revision surgery at a later point in time which by itself results in high rates of morbidity and complications. ${ }^{4-7}$

Total hip arthroplasty is a good treatment option in patients especially in the age group of 60 years and above as it is the salvage procedure in failed cases of both internal fixation as well as hemiarthroplasty. The aim of surgery in these patients is to provide them with a stable and functional hip and to mobilise the patients as early as possible in order to considerably reduce the rates of morbidity and mortality associated with them as well as to minimise the complications. ${ }^{8,9}$

The aim of this study was to evaluate the role of cemented total hip arthroplasty as the primary treatment option in fractures of the neck of femur in patients aged 60 years and above and to compare the functional outcome with the studies of various authors as available in literature.

\section{METHODS}

This study was conducted in the department of Orthopaedics, Saveetha Medical College and Hospital, Thandalam between January 2011 to January 2013. 45 patients with fractures of the neck of femur aged 60 years and above with a sound mind and who were willing for surgery and follow up were included in our study, while patients less than 60 years, patients with active hip or systemic infection, previously non ambulant patients, patients with pathologic fractures, patients with neurologic disorders and patients not willing for follow up were excluded. All patients were seen either at the outpatient or the emergency department and following admission, a detailed examination was done after stabilising the patient clinically. All relevant blood investigations were carried out and all medical systems were examined clinically. Any associated injuries were assessed and associated co morbid conditions were evaluated and documented in the case records. The patients were then evaluated radiologically and x-rays were taken which included $\mathrm{x}$-ray chest, standard views such as pelvis with both hips antero-posterior view and anteroposterior view of the affected hip with the limb in internal rotation in order to view the amount of the femoral neck available to plan for surgery. The fractures were classified according to Gardens classification. Preoperative planning for the surgery was done by templating in order to know the appropriate sizing of the femoral and acetabular components. All patients were taken up for the procedures after getting consent from them and obtaining the relevant medical and anaesthetic fitness for surgery. The procedures were done under either general or spinal anaesthesia under antibiotic cover. Injection cefazolin 1 gram and injection amikacin 500 milligrams were given at the time of induction of anaesthesia and were continued for 3 days, post operatively followed by 5 days of oral antibiotics. Prophylactic anticoagulant therapy was given in selected high risk patients who had co morbid conditions like diabetes, heart disease or morbid obesity for a total period of 5 days.

All procedures were performed by the same surgeon using the Modified direct lateral Hardinge's approach following standard described operative techniques. Bone cement was used in the fixation of the femoral and acetabular components. In the postoperative period, the patients were instructed to keep the operated limb in wide abduction using an abduction pillow in order to prevent dislocation of the hip. The patients were made to sit up on the same evening of surgery and the knee and ankle were actively mobilised. Static quadriceps exercises were started as well. The patients were mobilised on the first postoperative day with weight bearing with walker support based on the pain tolerance and compliance of the patient. First wound inspection was done on the third postoperative day and the drain tube was removed at that time and subsequent dressings were done at three day intervals. Suture removal was done on the $12^{\text {th }}$ postoperative day. $\mathrm{X}$ rays were taken in the postoperative period to check the position of the femoral and acetabular components. Femoral stem was assessed by dividing the proximal part of the femur into seven zones, three each on the lateral and medial sides and one below the tip of the stem. Only definite evidence of loosening was considered significant at the time of follow up. Acetabular cup loosening was assessed using the criteria of Hodgkinson et al. ${ }^{10}$ Any acetabular component, which had a continuous radiolucent line in all three zones, was considered to be loose. Heterotrophic ossification was classified using the system of Brooker et al. ${ }^{11}$ The patients were then discharged and asked to review at 3,6 weeks, 3, 6, 9 months and at 1 and 2 years for follow up. The hip was evaluated functionally according to the Harris hip score and all findings were recorded in the follow up records. Specific questions were asked regarding use of walking aids, capability of independent ambulation, use of public transport along with limb length measurements at each follow up. Trendelenberg's test was performed in all patients to assess the abductor mechanism. The data collected was analyzed using IBM SPSS version 22.0. Armonk, NY: IBM Corp. Continous variables were expressed as mean $\pm \mathrm{SD}$ and categorical variables were expressed as number and percentages. Chi square test was used in the comparison of categorical 
variables. A P value of less than 0.05 was considered to be statistically significant.

\section{RESULTS}

45 patients with fractures of the neck of femur were treated by primary cemented total hip arthroplasty and were studied from January 2011 to January 2013.There were 18 males and 27 females in our study with the ratio of males to females being 2:3. (Figure 1) The age of the patients ranged from 60 to 75 years of age with the mean age being 64.6 years. Maximum numbers of patients were in the 60-65 age group (Table 2). The most common mode of injury was a slip and fall accounting for $68 \%$ of the fractures followed by road traffic accidents and fall from a height (Table 3). Associated fractures were seen in 7 patients and were treated accordingly (Table 4). Left hip was more commonly involved with 29 of the patients having fractures of the left neck of femur (Figure 2). According to Gardens classification type 4 fractures were the most common accounting for $80 \%$ of the cases followed by type 3 (Table 5). Co morbid conditions were present in 25 patients in our study with hypertension (40\%) and diabetes mellitus $(24 \%)$ being the most common (Table 6). The period of stay in the hospital ranged from 12 to 18 days with the average being 14 days. Results were evaluated according to the Harris Hip Scoring system and excellent results were seen in 17 patients, good results in 24 patients and fair results in 4 patients. No poor results were seen. Average Harris hip score was 84.6 (range 76-94) at the last follow up with $91 \%$ of the hips having a good or excellent result (Table 7 ). The movements at the affected hip were recorded till the last follow up. There was average flexion of $84^{0}\left(80^{\circ}\right.$. $\left.90^{\circ}\right)$, abduction of $26^{\circ}\left(20^{\circ}-30^{\circ}\right)$ adduction of $21^{\circ}\left(15_{0^{-}}\right.$ $\left.25_{0}\right)$ internal rotation of $10^{\circ}\left(5^{\circ}-15^{\circ}\right)$ and external rotation of $32.5^{\circ}\left(20^{\circ}-40^{\circ}\right)$ average preoperative shortening was $2.13 \mathrm{~cm}$ (range $1-4 \mathrm{~cm}$ ). While 37 patients had an equal limb length post operatively, 8 patients had an average shortening of $1.1 \mathrm{~cm}$ (range $0.5-2 \mathrm{~cm}$ ).

\section{Table 1: Harris hip score}

\begin{tabular}{|c|}
\hline Pain \\
\hline None or ignores it (44) \\
\hline Slight, occasional, no compromise in activities (40) \\
\hline $\begin{array}{l}\text { Mild pain, no effect on ordinary activities, rarely } \\
\text { moderate pain with unusual activity; may take aspirin } \\
\text { (30) }\end{array}$ \\
\hline $\begin{array}{l}\text { Moderate pain, tolerable but makes concession to } \\
\text { pain. Some limitation of ordinary activity or work. } \\
\text { May require occasional pain medication stronger than } \\
\text { aspirin (20) }\end{array}$ \\
\hline Marked pain, serious limitation of activities (10) \\
\hline Totally disabled, crippled, pain in bed, bedridden $(0)$ \\
\hline Limp \\
\hline None (11) \\
\hline Slight (8) \\
\hline Moderate (5) \\
\hline Severe $(0)$ \\
\hline
\end{tabular}

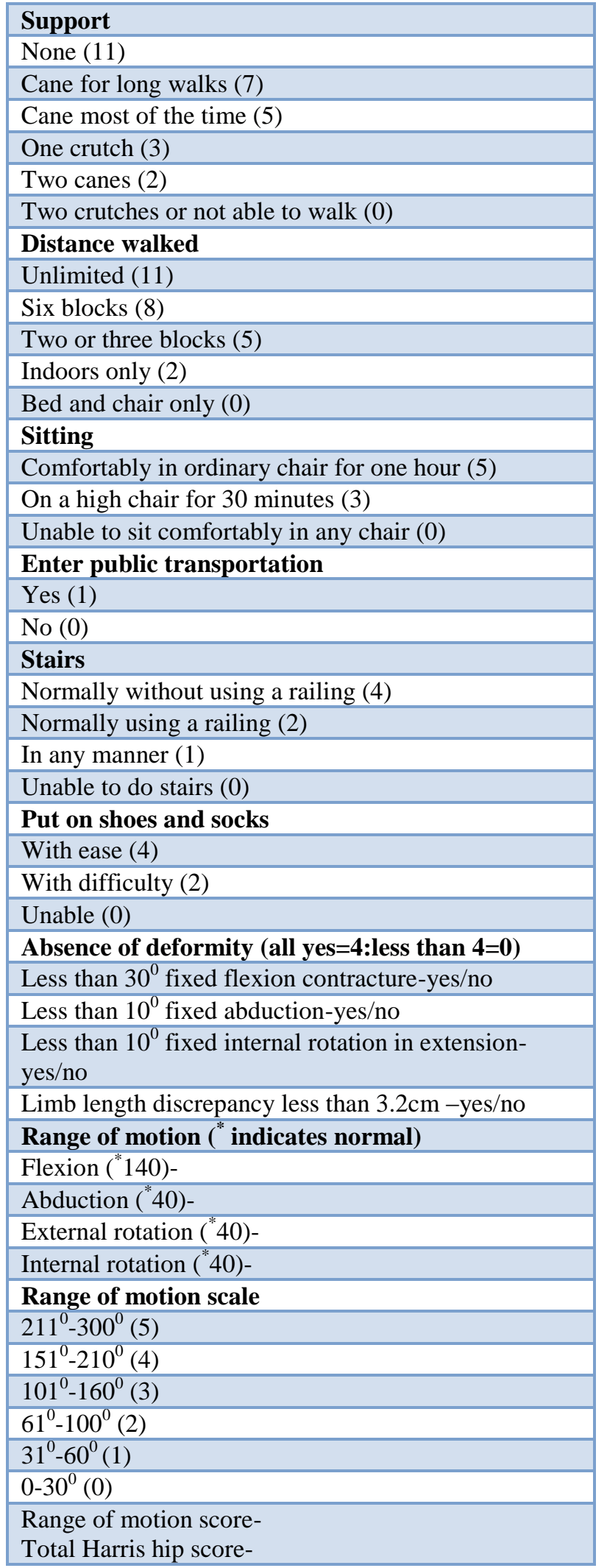

Till the last follow up 3 patients (6\%) had slight or occasional pain, which was not related to activity, did not limit function and disappeared with rest. One patient had mild pain with unusual activity for which she took analgesics. No patient took regular analgesics or complained of moderate to severe pain so as to limit 
ordinary activity or work. 9 patients $(20 \%)$ had slight limp and 1 patient $(2 \%)$ had moderate limp at the last follow up. $5(11 \%)$ patients were using a single cane in the opposite hand, $8(17 \%)$ used it occasionally only when walking for long distance. 1 (2\%) patient was using a walker for support.

Table 2: Age distribution.

\begin{tabular}{|llll|}
\hline $\begin{array}{l}\text { S. } \\
\text { No. }\end{array}$ & Age(years) & $\begin{array}{l}\text { Number of } \\
\text { patients }\end{array}$ & $\begin{array}{l}\text { Percentage } \\
(\%)\end{array}$ \\
\hline $\mathbf{1}$ & $60-65$ & 30 & 67 \\
\hline $\mathbf{2}$ & $66-70$ & 10 & 22 \\
\hline $\mathbf{3}$ & $71-75$ & 5 & 11 \\
\hline
\end{tabular}

Table 3: Mode of injury.

\begin{tabular}{|clll|}
\hline $\begin{array}{l}\text { S. } \\
\text { No. }\end{array}$ & $\begin{array}{l}\text { Mode of } \\
\text { injury }\end{array}$ & $\begin{array}{l}\text { Number of } \\
\text { patients }\end{array}$ & $\begin{array}{l}\text { Percentage } \\
(\%)\end{array}$ \\
\hline $\mathbf{1}$ & Slip and fall & 31 & 68.8 \\
\hline $\mathbf{2}$ & $\begin{array}{l}\text { Road traffic } \\
\text { accidents }\end{array}$ & 9 & 20 \\
\hline $\mathbf{3}$ & $\begin{array}{l}\text { Fall from a } \\
\text { height }\end{array}$ & 5 & 11.2 \\
\hline
\end{tabular}

Table 4: Associated fractures.

\begin{tabular}{|lll|}
\hline S. No. & Associated fractures & Number of patients \\
\hline $\mathbf{1}$ & Vertebral compression & 3 \\
\hline $\mathbf{2}$ & Distal radius & 2 \\
\hline $\mathbf{3}$ & Proximal humerus & 1 \\
\hline $\mathbf{4}$ & Clavicle & 1 \\
\hline
\end{tabular}

Table 5: Cases according to Gardens classification.

\begin{tabular}{|llll|}
\hline $\begin{array}{l}\text { S. } \\
\text { No. }\end{array}$ & Gardens type & $\begin{array}{l}\text { Number of } \\
\text { patients }\end{array}$ & $\begin{array}{l}\text { Percentage } \\
(\boldsymbol{\%})\end{array}$ \\
\hline $\mathbf{1}$ & Type 1 & 0 & 0 \\
\hline $\mathbf{2}$ & Type 2 & 0 & 0 \\
\hline $\mathbf{3}$ & Type 3 & 9 & 20 \\
\hline $\mathbf{4}$ & Type 4 & 36 & 80 \\
\hline
\end{tabular}

Table 6: Co morbid conditions.

\begin{tabular}{|clll|}
\hline $\begin{array}{l}\text { S. } \\
\text { No. }\end{array}$ & $\begin{array}{l}\text { Comorbid } \\
\text { conditions }\end{array}$ & $\begin{array}{l}\text { Number of } \\
\text { patients }\end{array}$ & $\begin{array}{l}\text { Percentage } \\
(\%)\end{array}$ \\
\hline $\mathbf{1}$ & Hypertension & 10 & 40 \\
\hline $\mathbf{2}$ & Diabetes mellitus & 6 & 24 \\
\hline $\mathbf{3}$ & $\begin{array}{l}\text { Cardiovascular } \\
\text { disorders }\end{array}$ & 2 & 8 \\
\hline $\mathbf{4}$ & COPD & 3 & 12 \\
\hline $\mathbf{5}$ & $\begin{array}{l}\text { Hypertension and } \\
\text { Diabetes }\end{array}$ & 4 & 24 \\
\hline
\end{tabular}

3 patients had radiological signs of preoperative hip osteoarthritis. Postoperative radiographs showed that the orientation of femoral component was neutral in 37 hips (83\%), valgus in 5 hips (10\%), and slight varus in 3 hips
$(7 \%)$. Average acetabular inclination was $43^{\circ}\left(35-55^{\circ}\right)$ no radiolucent zones, no horizontal or vertical migration of the cup or change in its inclination was seen till last follow up. No vertical migration of the femoral stem or change in its position was seen till last follow up.

Table 7: Clinical results according to Harris hip score.

\begin{tabular}{|lll|ll|}
\hline $\begin{array}{l}\text { S. } \\
\text { No. }\end{array}$ & $\begin{array}{l}\text { Harris hip } \\
\text { score }\end{array}$ & Grading & $\begin{array}{l}\text { Number of } \\
\text { patients }\end{array}$ & $\%$ \\
\hline $\mathbf{1}$ & $90-100$ & Excellent & 17 & 38 \\
\hline $\mathbf{2}$ & $80-89$ & Good & 24 & 53 \\
\hline $\mathbf{3}$ & $70-79$ & Fair & 4 & 9 \\
\hline $\mathbf{4}$ & $<70$ & Poor & 0 & 0 \\
\hline
\end{tabular}

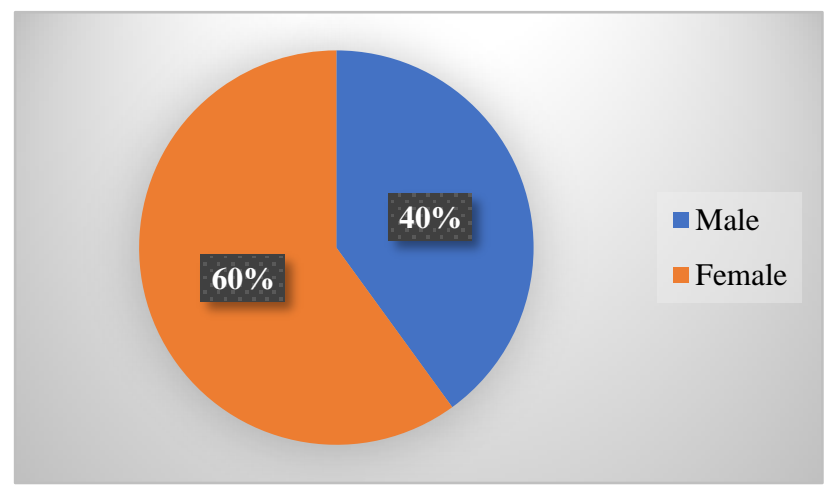

Figure 1: Sex distribution.

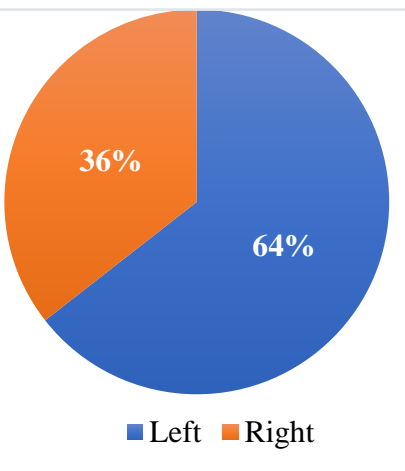

Figure 2: Side dominance.

Nine patients $(20 \%)$ developed urinary tract infections in the postoperative period which responded to antibiotics according to culture sensitivity. 2 patients (4\%) developed grade II bedsores which healed eventually. 1 patient, a known case of COPD developed postoperative acute exacerbation of COPD and had a prolonged ICU stay but recovered satisfactorily following treatment. No other medical conditions like deep vein thrombosis, myocardial infarction, cerebrovascular accident etc. were seen. 6 cases had proximal migration of the trochanteric sliver while one patient had a superficial skin infection which responded well to antibiotics. No other local complications like deep infection, dislocation, heterotrophic ossification, loosening or migration of cup/stem were seen. 


\section{DISCUSSION}

Fractures of the neck of femur are common injuries which are seen in the orthopaedic department and the incidence of these fractures has been on the rise due to the increased longevity of the population as seen by demographic studies. These fractures are often associated with considerable rates of morbidity mostly due to associated co morbid conditions and mortality due to age related complications. In the past conservative management had a role to play in its management, but due to the increased incidence of complications such as non-union and the effects of long term immobilisation and recumbency, it has largely been given up and only reserved in cases where the patient has a poor general condition and cannot be taken up for the procedure. Internal fixation is the treatment of choice in young individuals where preservation of the head of femur is the aim of surgery. In the elderly population, the trend is more towards replacing the head rather than fixing it by performing either a hemiarthroplasty or a total hip arthroplasty. Bipolar hemiarthroplasty is quite commonly done in patients with a good outcome but the long term incidence of complications such as acetabular erosion and protusio acetabuli are its limitations which would require a revision surgery after a point of time. Total hip arthroplasty has always been the salvage procedure for failure of both internal fixation and hemiarthroplasty and hence in this study we wanted to evaluate the role of Total hip arthroplasty as a primary treatment option in patients with fracture of the neck of femur aged 60 years and above.

45 patients with fractures of the neck of femur in individuals aged 60 years and above were managed with total hip arthroplasty and were evaluated functionally using Harris hip score and radiologically using established parameters. Maximum numbers of patients were in the 60-65 age group. The most common mode of injury was a simple slip and fall which was responsible for the fracture to occur due to the osteoporotic nature of the bone while others like road traffic accidents and fall from a height were also seen. $80 \%$ of cases were type 4 as per gardens classification. Most of the patients had associated co morbid conditions like Hypertension, Diabetes Mellitus, Cardiovascular disease and Copd, which in old age could account for a significant amount of morbidity and mortality. In a study by Coates and Armour, there was a reported mortality rate of $29 \%$ due to medical complications such as cardiovascular disease and pulmonary embolism. ${ }^{12}$ The mortality rate reported by Delamarter and Moreland was $12 \%$ at the end of one year. ${ }^{13}$ Due to advances in medical diagnostics and management, there seems to be a definitive decrease in the rates of mortality and morbidity associated with these fractures especially in the older population. There was a delay in performing surgery in a few of our patients, which was expected due to the associated co morbid conditions and after a thorough work up and after getting medical and anaesthetic clearance, the procedures were done.

All procedures were done using the direct lateral approach due to the fact that this approach is associated with lower rates of dislocation and possibly a lower risk of infection as compared to the more traditional posterior approaches used by most surgeons. However, the risk of abductor damage is to be kept in mind while using this approach leading on to possible abductor weakness and limp post-surgery.

All procedures were done under antibiotic cover which included inj. Cefazolin $1 \mathrm{gm}$ and inj. Amikacin $500 \mathrm{mg}$ which was given at the time of induction of anaesthesia and continued for 3 days, post operatively. There have been studies which have shown that prophylactic antibiotics significantly reduce the incidence of sepsis in arthroplasty surgeries. In a study by Bryan et al, they observed that the incidence of sepsis was quite low in surgeries which were performed under antibiotic cover. ${ }^{14}$ In another study by Nelson et al, the reported infection rate was $5.8 \%$ without the use of antibiotics while it was $1.3 \%$ with antibiotic usage. ${ }^{15}$ There was only one case with superficial skin infection in our series which settled down well with antibiotics. No cases with deep infection were seen.

All patients were graded according to Harris hip score and the results were analysed and documented accordingly at the time of follow up. In a study by Taine and Armour, good to excellent results were seen in $70 \%$ of patients while Gregory et al reported a $94 \%$ good to excellent results in their study. ${ }^{16,17}$ In our study, according to the Harris hip score, $91 \%$ of patients had good to excellent results which compares well with the studies of other authors. $94 \%$ of the patients in our study were pain free post-surgery negating the need for the use of analgesics. Six of our patients had proximal migration of the trochanteric sliver which resulted in a painless limp possibly due to the shortening of the abductor mechanism. In a study by Greenough and Jones, they observed that out of their series of cases of total hip arthroplasty, $32 \%$ of cases requires a revision surgery due to loosening of components. ${ }^{18}$ In a study by Gebhardt et al the revision rate which was quoted was $2-3 \% .{ }^{19}$ No evidence of loosening or migration of the components were seen at the time of the last follow up.

Medical complication like UTI and bedsores were seen in $26 \%$ of the patients. Around $31 \%$ of the patients were using walking aids, most of them a cane, in the opposite hand as a safety measure. More over many elderly patients do need some kind of support even otherwise.

None of the patients in our study had complications of immobilization like deep vein thrombosis, pneumonia or atelectasis. Only two patients developed grade II bed sores which healed on mobilisation. Early mobilisation 
was the main reason for the significant reduction in these medical complications.

A literature review showed about $10-12 \%$ dislocation rate in primary THA done for fractures of neck of the femur, which is one of the reasons preventing orthopaedic surgeons worldwide to go for a primary THA in this fracture. In a study by Sim and Stauffer, there was a reported dislocation rate of $10.7 \%$ while it was reported to be $8 \%$ in a study by Coates and Armour. ${ }^{20,12}$ None of the patients in our series had a dislocation. The lack of dislocations in our study could be attributed to the fact that proper soft tissue handling was done and closure of the capsule was also performed after implantation of the prosthesis. The lateral approach was also a contributory factor. An average of $1.1 \mathrm{~cm}$ of shortening was seen in 8 of our cases, but there were asymptomatic and were comfortable while walking and they did not require a sole or a heel rise.

Excellent results were obtained in $38 \%$, good results in $53 \%$ and fair results in $9 \%$. None of the patients had a poor result. $91 \%$ of the patients were pain free and independently mobile at the last follow up. No component loosening or migration was seen at the period of follow up. Distal femoral cortex perforation was not seen in any of our cases.

Prosthetic replacement has become established as the standard of care in elderly patients with displaced femoral neck fractures. While surgeons have traditionally preferred hemiarthroplasty to total hip arthroplasty, the current level of evidence does not show superiority of one procedure over the other. The primary reason why total hip arthroplasty is avoided as a primary treatment option in fractures of the neck of femur is because of the rates of dislocation following the procedure. With good surgical technique and proper soft tissue handling and by using the lateral approach, the above complication is avoidable as shown in our series. Therefore, we consider primary Total hip arthroplasty to be a viable option for treatment in a selected group of previously independently mobile patients with fractures of the neck of femur. Longer follow up studies are recommended to assess the hip function, implant survival and complications related to wear and loosening in the long term.

\section{CONCLUSION}

By this study, we conclude that cemented Total hip arthroplasty is a very useful procedure for the primary treatment of femoral neck fractures in the elderly population. We would recommend the lateral approach for this procedure as it's associated with a lower rate of dislocation. This procedure markedly improves the functional status of the patient in terms of early mobilisation, and gives good clinical results. We strongly recommend its use as the primary option in the management of these fractures.
Funding: No funding sources

Conflict of interest: None declared

Ethical approval: Not required

\section{REFERENCES}

1. Alffram PA. An epidemiological study of cervical and trochanteric fractures of the femur in an urban population. Acta Orthop Scand. 1964;65:1-109.

2. Hopley C, Stengel D, Ekkernkamp A, Wich M. Primary total hip arthroplasty versus hemiarthroplasty for displaced intracapsular hip fractures in older patients: systematic review. BMJ. 2010;340:2332.

3. Barnes R, Brown JT, Garden RS, Nicoll EA. Subcapital fractures of the femur. J Bone Joint Surg. 1976;58:2-24.

4. D'Arey J and Devas M. Treatment of fracture of femoral neck by replacement with Thompson's prosthesis. J Bone Joint Surg. 1975;58:279-86.

5. Jhonson JTH and Crothers O. Nailing versus prosthesis for femoral neck fractures. J Bone Joint Surg. 1975;57:686.

6. Riska EB. Prosthetic replacement in the treatment of subcapital fractures of femur. Acta Orthop Scand. 1971;42:281.

7. Siroski JM, Barrington R. Internal fixation versus hemi- arthroplasty for the displaced subcapital fracture of femur. A prospective study J Bone Joint Surg. 1981;63:357-61.

8. Michael Saleh, George Murdoch. In defence of gait analysis. J Bone Joint Surg. 1985;67:237-41.

9. Barnes R. Problems in the treatment of femoral neck fractures. Proc R Soc Med. 1970;63(11):1119-20.

10. Hodgkinson JP, Shelly P and Wrobeuzki BM. The correlation between radiographic findings at the bone cement function of the socket in Charnley low friction arthroplasties. Clin Orthop. 1988: 228.

11. Booker AF, Boweman JVV, Robinson RA. Ectopic ossification following THR incidence and method of classification. J Bone Joint Surg. 1973;55:16-29.

12. Coates RL, Armour P. Treatment of subcapital femoral fracture by primary total hip replacementInjury. 1979;11(2):132-5.

13. Delamarter R, Moreland JR. Treatment of acute femoral neck fracture with total hip arthroplasty. Clin Orthop. 1987;218:68-74.

14. Bryan CS, Morgan SL, Caton RJ, Lunceford EM. Cefazolin versus Cefamandole for prophylaxis during total hip arthroplasty. Clin Orthop. 1988;228:117-22.

15. Nelson CL, Green TG, Porter RA, Warren RD. One day versus seven days of preventive antibiotic therapy in orthopaedic surgery. Clin Orthop. 1983;176:258-63.

16. Taine WH, Armour PC. Primary hip replacement for displaced subcapital fractures of the femur. $\mathrm{J}$ Bone Joint Surg Br. 1985;67(2):214-7. 
17. Gregory RJ, Wood DJ, Stevens J. Treatment of displaced subcapital fractures with total hip replacement. Injury. 1992;23:168-70.

18. Greenough CG, Jones JJR. Pr THR for displaced subcapital fracture of the femur. J Bone Joint Surg. 1988;70:639-43.

19. Gebhardt JS, Namstutz HC, Zinar DM, Dorrey FJ. Comparison of the total hip arthroplasty and hemiarthroplasty for the treatment of acute fractures of the femoral neck. Clin Orthop. 1992;282:123-31.
20. Sin FH, Stauffer RN. Total hip arthroplasty in acute femoral neck fracture Inst. Course Lect. 1980;29:916.

Cite this article as: Subash Y, Jagadeesh B, Ravikrishna R, Manickam P. The role of primary cemented total hip arthroplasty in the management of fractures of the neck of femur in the elderly population. Int J Res Orthop 2018;4:8-14. 